\title{
SURVEY GUIDELINES AND ITS READING CRITERIA FOR MONITORING AND TRANSMITTING CULTURAL HERITAGE VALUES
}

\author{
A. De Masi \\ ABC, Dept. of Architecture, Built Environment and Construction Engineering, Milan Polytechnic, II School of Architecture, Via \\ Durando 10, 20158 Milan - alessandro.demasi@polimi.it - alessandro.demasi@unina.it
}

\author{
Commission VI, WG VI/4
}

KEY WORDS: Analysis and Interpretation of Material Systems, Survey Guidelines, Reading Criteria, Drawing as a Laearning System of Architectural Heritage, Relief as a Knowledge Framework, 2D/3D digitization of Cultural Heritage

\begin{abstract}
:
The paper describes reading criteria for an analysis and interpretation of material systems in relation to a built space, survey guidelines and its reading criteria for Cultural Heritage $(\mathrm{CH})$ values'monitoring and transmission. In addition, integrated systems of digital technologies and 2D/3D digitization of $\mathrm{CH}$ are introduced for an effective and accurate reading of Venice and Milan's monuments. Specifically, the guidelines for an architectural survey allow to organize and document historic monuments information, and to identify the significant cultural/physical elements of our past in order for them to be preserved and protected for future generations. In addition, in this paper the studied projects introduce a combination of virtual technologies and historical reality with experimenting innovative solutions for $\mathrm{CH}$. From the methodological point of view, this study has made use of the identification of levels of study (LS) differentiated, each of which is capable of identifying categories.
\end{abstract}

\section{INTRODUCTION}

\subsection{Objectives}

The paper describes reading criteria for an analysis and interpretation of material systems in relation to a built space, survey guidelines and its reading criteria for $\mathrm{CH}$ values'monitoring and transmission. In addition, integrated systems of digital technologies and 2D/3D digitization of $\mathrm{CH}$ are introduced for an effective and accurate reading of Venice and Milan's monuments. In this paper the studied projects introduce a combination of virtual technologies and historical reality with experimenting innovative solutions for $\mathrm{CH}$. The new digital technologies allow to detect info-graphics representations that can be easily adapted to the different needs of scholars from the field. The integrated digital architectural survey not only represents a critical analysis of the city's historical architecture but is also a "container" for the multiscale cataloging of the architecture that returns a threedimensional numerical model. Specifically, the guidelines for an architectural survey allow to organize and document historic monuments information, and to identify the significant cultural/physical elements of our past in order for them to be preserved and protected for future generations. In the second part of the paper, I will analyze the interpretation of material systems and intangible assets, the importance of drawing as a learning system of architectural Heritage, the route to knowledge and the steps to study and monitoring $\mathrm{CH}$ 's state of preservation. In the third part, I will report reading criteria for architectural surveys and $\mathrm{CH}$ 's digitization.

\section{MAIN BODY}

\subsection{Research Methodology}

It was identified a methodology for reading that can return a survey aimed at evaluating changes induced by simultaneity through the decomposition of multi-scale representation of the parties examined by Digital Representation Platform (DRP) (De Masi, 2014). I identified relief guidelines aimed at the realization of architectural sites multi-scale models. This was made possible by the geo-referencing process consisting in the insertion of local systems in less local systems. The research was articulated according to the DRP of the architectural and the urban landscape in order to improve current policies and standards. It is based by heritage information with integrated activities of recording, documentation, and information management to acquire knowledge, understand values and ensure long-term maintenance and conservation of heritage places. The benefits of integrated digital survey describing the physical configuration of sites and their physical condition at known points in time fall into two broad areas: 1- conservation planning and management; 2- provision of a permanent archival record. These were the steps followed for multi-representation: 1-Visual frameworks in the urban space. 2- Criteria of heritage significance and principles of evaluation of $\mathrm{CH}$ assets. 3- Study of current methods of 2D/3D digitization intended and Open Source for $\mathrm{CH}$ preservation. 4- Study of the relief procedures with integrated laser scanning and photogrammetry. About the relief of the elevated parts, scanning and relief stance optimization were considered. 5- Study of the relief integration methods applied to the plan and the elevated parts in order to define a one-3D system. This was to identify the invariant with respect to the scale of representation in the geometry of the object and then proceed to the geo-referencing. 6- Study of best practices for the realization of $3 \mathrm{D}$ models that are mapped to different nominal scales and with different levels of detail. 7Study of scale changes in the individual models (site, architecture, details) with simplifications based on the selection and activation of geometric information from different nominal scales. 8- Accurate documentation of each cultural object, encouraging an integrated interdisciplinary approach. 9- Study of Open Source tools and software for $\mathrm{CH}$ fruition and conservation. From a methodological perspective, the identification of LS has allowed me to identify categories of dimensional, constructive, formal and cultural values. Therefore, I started from the existing data collection organized by categories and subcategories, to understand the current relationship between identity signs and contemporary signs. For space reasons, in this paper only criteria of heritage significance, principles of $\mathrm{CH}$ assets evaluation, current 
methods of 2D/3D digitization, and Open Source for $\mathrm{CH}$ preservation will be reported.

\subsection{Analysis and Interpretation of Material Systems and Intangible Assets}

An historic context might encompass the development of an area taking into account its history, architecture, archeology and culture. It also might identify the significant patterns that individual monuments represent within that context. The guidelines on criteria and conditions for evaluation of $\mathrm{CH}$ Assets in relation to a built space were as follows: 1- Historic and aesthetic significance. It is related to its style, technical excellence, beauty, quality of design and execution. 2Scientific or research significance. 3- Social and spiritual significance. The analysis also was based on the following criteria for complex representation: 1- Intrinsic significance (Authenticity, Extent/Completeness, Integrity, Continuity of use/demonstration, Corpus of evidence/study). 2- Contextual significance (Rarity, Representativeness /Uniqueness, Diversity, Physical context, Threat/fragility). 3- Associative significance (Historic interest and association, Aesthetic attributes).

\subsubsection{Drawing as a Laearning System of Architectural Heritage}

The introduction of digital systems for analysis and CH's interpretation included: 1- a drawing as a complex and comprehensive system capable of combining metric and dimensional qualities with sensitive-perceptive qualities. 2- a drawing as a complex multidimensional system of an architectural reality representation. In addition, the interrelation of the concepts of dimensional representation to other aspects related to the culture of antiquity and conservation. Two spheres of action can be defined: 1- collecting perceptual and visual, metric or dimensional data about the place of study for the representation of the empirical, physical and geometric space. The objective is to explore the relations between the elements of a given space-object. 2- the intentional evaluation of the data collected to establish criteria for segregation, distinction and order in the representation of the architecture. This occurs when the concept of the physical scale appears as a metric relation between real and represented dimensions that depends on the amount and quality of the information to be supplied. Therefore, a graphic analysis for an effective CH's evaluations (Docci, 2009) will be carried out with study steps as it follows: 1- A functional analysis to point out space organization, orizontal and vertical paths, surfaces for different functions, natural lightning and orientation, technological structures. 2- Analysis of the pillar and continued supporting structure, and the archivaulted system. 3- Analysis of the architectural elements or a formal analysis provided with a geometrical and proportional study; elements of side closures: facades; elements connected to the ground; roofing elements: roofs and terraces; joint elelments in between side closures: corner solutions; links between the outside and the inside; atrium access; vertical connection elements: stairs and ramps. 4- Spatial analysis. 5- Analysis of the relationship between the construction and its context, a necessary planimetry report on paths, relationships among the different architectonic emergencies, a visual perspectical analisys, relationships with green spaces, etc.

\subsubsection{Drawing as a Graphic Dimensional Reconstruction of} Buildings and Analysis of Architecture's Intrinsic Qualities

The drawing used was not just a graphic dimensional reconstruction of buildings, but also an analysis of architecture's intrinsic qualities. In the classical period, the Roman architectural legacy was the graphic reference and object of study intended for an architectural survey. In the Renaissance, the representation constituted the conquest of the figurative autonomy of the drawing over pictorial representation, both in terms of the linear representation of the perspectives (Ghirlandaio, Dosio, Peruzzi) and in the use of orthographic projections (Serlio, Palladio), until the first complex drawings related to cross-sections (Rafaello) and axonometrics appeared (Celis et al, 2011). The Florentine humanism considers drawings as bases of any figurative experience, unifying the intellectual momentum with the artistic practice. Hence the beginning of ' 400 differentiation between architecture and engineering. During the Renaissance the design, hitherto seen as tools for understanding the universe, loses its importance and is no longer an arrival point but rather an exercise that is just an intimate necessity for an immediate experience. In the $17^{\text {th }}$ and the $18^{\text {th }}$ Centuries, such theoretical problem is shrinked into a discussion about the superiority of the design or the color. The birth of academies clearly indicates that the problem becomes of scholastic nature; as a matter of fact, master's designs become textbooks. Desgodetz was the first to develop a systematic and scientific study of Roman architectural heritage, laying down the foundations of modern architectural survey drawing. (Celis et al., 2011). The appreciation for architectural heritage was consolidated and developed both in its scientific-archaeological aspects through survey drawings as well as in its aesthetic-scenic aspects, which characterise and make the location unique (Celis et al., 2011). This added value was made patent by the double language Piranesi used to describe the Roman ruins with constructive precision and to express the spectacular images that transformed these into presences that were intrinsically tied to the place in which they were located. (Celis et al., 2011). (Figure 1). Luigi Vanvitelli is another exceptional figure at the end of 1700. His mastery in the ink drawing watercolor (see School of Carlo Fontana) is well-known, the sign is safe and fast. He accentuates the color contrasts with watercolors, creatingå a symbiotic relationship between painting and architecture. His first idea is sketched gradually in more and more elaborate plans and sections, only to later become architerctural drawings. The space is represented in a vedutistico mode thanks to his father Gaspar teachings, clearly oriented towards a vedutistica opticalperspective; also, he shows how architecture should not be defined only through outer space but also in its details, such as a decoration. Luigi Vanvitelli will focus on the following aspects: 1- perception and analysis for the possession of the space. 2space is only one (no distinction between natural and ideal space, pictorial and architectural space). 3- Spectacular or fantastic space is one that does not differ from the natural space (see Juvarra, Piranesi where there is a close relationship between spatial figurative fantasy and concrete architectural reality). 4- passion for the opera and scenic design. (Figure 2). In the nineteenth century, it is evident that a double language existed, and was expressed through drawings, to describe architectural heritage which, with the disappearance of the classical reference, extended to all styles and eras (Lewis, Violet le Duc) and was defined either through precise scientificarchaeological reproductions or drawings in which the ruins were the object of contemplation, transmitting memory and characterising the location and landscape (Celis et al., 2011). Drawings that basically reproduced typified models, orders and archetypes during the classical period evolved into a study of the monument defined by two aspects, one that is scientificanalytical and another that is aesthetic-scenic (see Schinkel), as two different ways of understanding the architectural legacy (Celis et al., 2011) (Figures 3, 4). This duality was also 
reflected in the development of twentieth century courses of study that basically divided architectural drawing, and consequently the drawing of architectural heritage, into two distinct spheres: "technical" drawing that consisted basically in defining the dimensional qualities of the object by using measurable systems of representation (basically, projections) and "artistic" drawing focused on expressing architectural qualities more closely tied to perception than description (Celis et al., 2011).

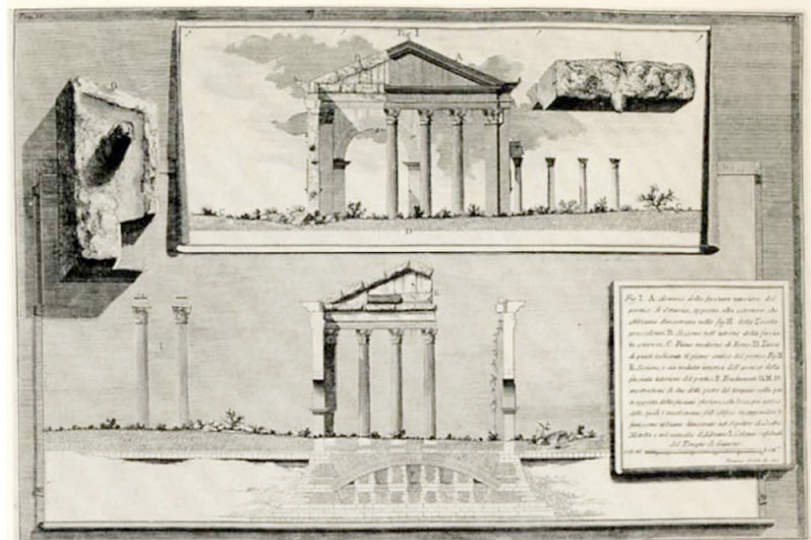

Figure 1- Piranesi, interior facade Ottavia colonnade. Facade sections
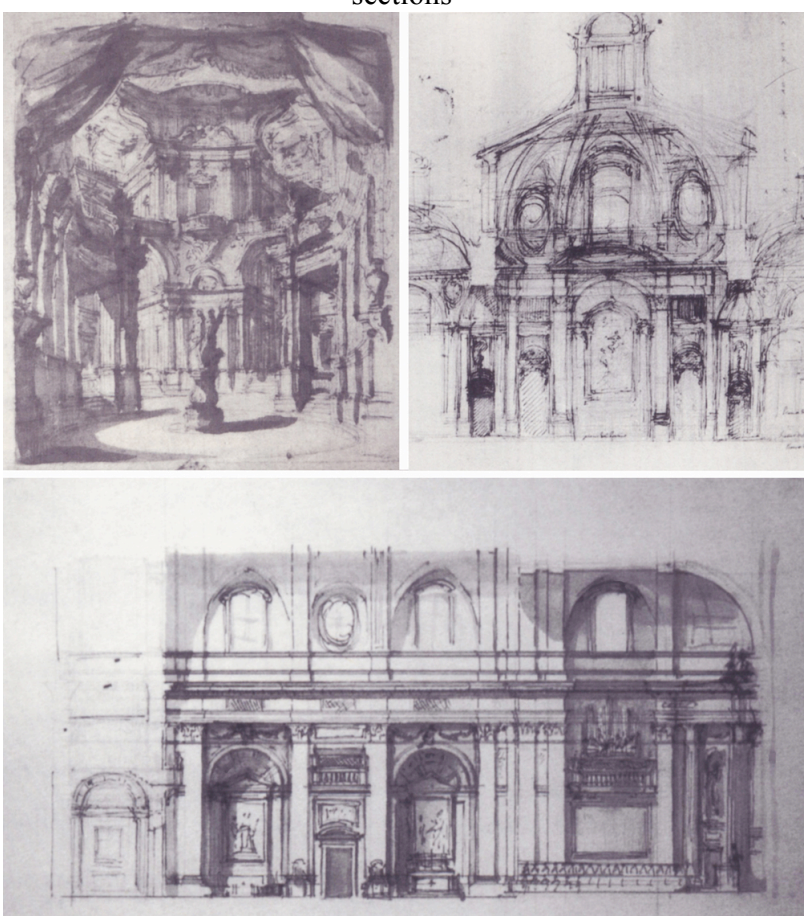

Figure 2 - Vnvitelli, L. From left above, Scene for Tito Manlio (inventory 1687), Longitudinal section of the Missions church in Naples, Longitudinal Section of the church of SS. Marcellino and Festo in Naples, Italy

\subsection{Relief as a Knowledge Framework: Multidimension and Multidiscipline}

Architectural survey is a process for identifying and gathering information about historic architectural buildings. The architectural survey is an operation to learn about the work as a whole, grasp its dimensional, constructive, formal and cultural values (Docci \& Maestri, 2009). It is to put in place a complex procedure that determines the in-depth knowledge of the work to detect, through a critical reading of the drawings made.

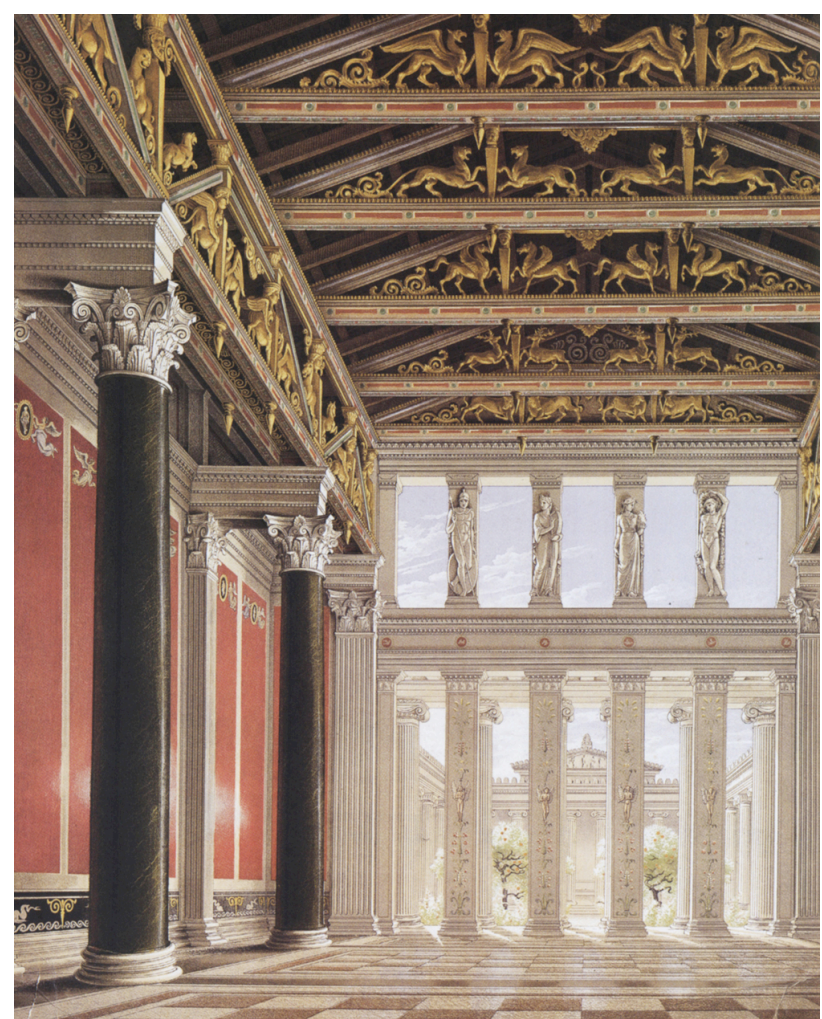

Figure 3 - Schinkel, K.F. Royal Palace in the Acropolis. Inside the vast reception room

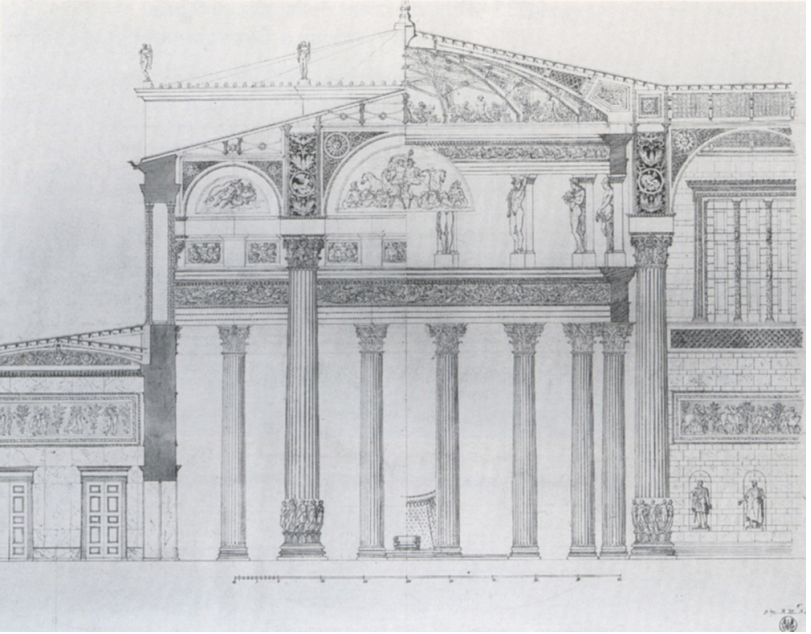

Figure 4 - Schinkel, K.F. Cross sections of the Throne Room, 1835

This will allow researchers to comprehend the construction phasesand transformations of the buildings studied. It can be used in a wide range of works, particularly in the architectural renovations, architectural analyses, archaeological researches, and architectural heritage census. The steps that I followed started from: 1-knowledge of the work to detect with the choice of survey techniques. 2- Architectural survey. 3- graphical representation. 4- reading of the work through the elaborate relief. 5- search of the historical record, the archive sources and bibliography. Architectural drawings concerned: 1- "Detection of the relationship between work to study and context" (scale 1: 10,000). 2 - "Dimensional relief " through drawings of plans, elevations and sections of the draft report (polygonal, trilaterations, shares), scale 1:50. 3- "Architectural survey" that involves the preparation of plans, elevations and 1:50 sections where all the important structures regarding the buildings 
studied are reported (vaults, roofing, flooring, fixtures, etc.). 4 "Detection of constructive and decorative details" of architectural orders, technical and construction details - 1:20 and 1:1 scale. 5- "Survey of the walls" with reference to the building modules, materials and their finishes, plasters and coatings. 6- Relief (hue, texture of the material and the kind of color). 6- Processed themes: geometry and proportion of buildings. Among the planimetric detection methods, the following were used: 1- trilateration. 2- detection for polar coordinates or radiation. 3- detection for polygonal. In particular, I used the direct method (employed in most architectural reliefs and indispensable for the realization of the plants and of the edifice sections), the instrumental method (complementary to the direct one and photogrammetric), and the photogrammetric method (used to get a considerably precise relief). Freehand drawings executed with the direct detection method and the technical design are presented in Figure 6. The work done for the Royal Palace in Milan follows the above structure. In particular: 1- Design and project detection of the ground floor plan (PT). 2- Measures survey for plant PT. 3Design and project tracking plants of the upper floors. 4measures survey of the upper floor plants. 5- Measures survey of the building section. 6- Project survey of prospects. 7Measures survey of the building elevation. 8- Survey project of architectural details. 9- Graphical representation of plants, sections, elevations and architectural details. (Figures 5, 6, 7, 8). As for the surrounding environment and the shape of the object, the survey project is oriented towards a prevalent use of $3 \mathrm{D}$ scanning. The survey was conducted by integrating 3D Leica ScanStation 2 scanner functions and Leica TCR 1201 R300 total station. It was also made an extensive photographic campaign. At the same time an open polygonal was built from which 40 support points were measured. Such points were materialized in place by as many aims. These latter have been subdivided into two types: a general with a sample spacing of $5 \times 5 \mathrm{~mm}$ and a detailed one of $2 \times 2 \mathrm{~mm}$. The double measuring of the target is the heart of the discovery protocol with a rotary translation of the 3D cloud on the topographic points. This occurred with the collimation of homologous points represented by the aims. The survey represents the body of a theoryoperation, through which we come to know the material elements of a CH (Docci \& Maestri, 2009). It should emphasize the multidimensional and multidisciplinary nature of this process which effectively provides a system for collecting, interpreting and storing quantitative and qualitative knowledge. With regard to the multidimensionality, it is worth recalling some basic concepts related to the so-called culture of space control. The geometric model, subject to a representation process, turns into a two-dimensional graphic model, that is a guaranteeing tool of the graphic model's control mechanisms. The geometrical model reconstructed in a virtual form becomes a 3D digital model. Based to this approach, the multidimensional reality is reduced to its geometric essence. In the survey's development, one can notice a dichotomy between the phase of data acquisition, increasingly dependent on the use of new "objective" 3D scanning technologies, and the ways in which the analysis is carried out in place of the studied object. The traditional approach, in this case, would consider the detection phase as complimentary of a preliminary study phase able to set the measurement possibilities. Detection and analysis would basically merge into one act. Most recent techniques have actually clearly separated the two moments. Photogrammetry is cited, as it checks out the project's feasibility through necessary topographic measures that will allow a stereophotogrammetric model generation. Here, the phase of data acquisition appears clearly distinct from the other. This approach is also suitable to the $3 \mathrm{D}$ scanning technology.
All these considerations outlines how the relief phase must be part of a broader knowledge framework where it is well recognized the border line between data acquisition and selection and elaboration criteria of the data base.
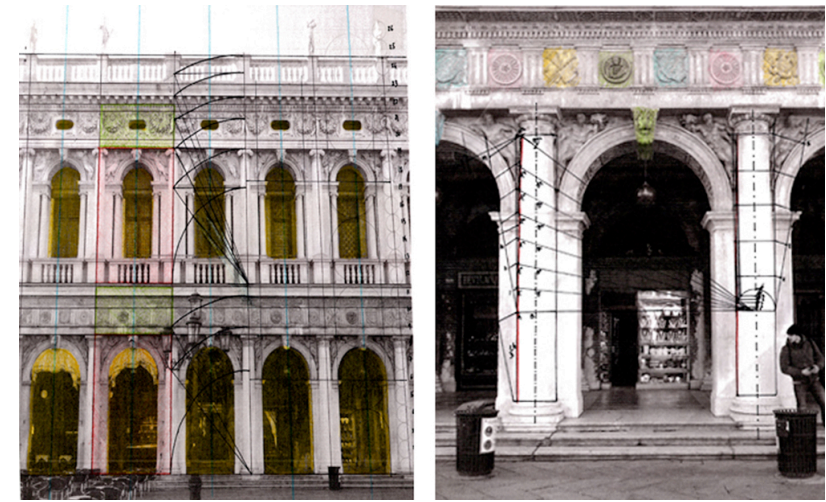

Figure 5 - Photographic survey of the different facades with proportioning schemes based on tilting the diagonal of the square base

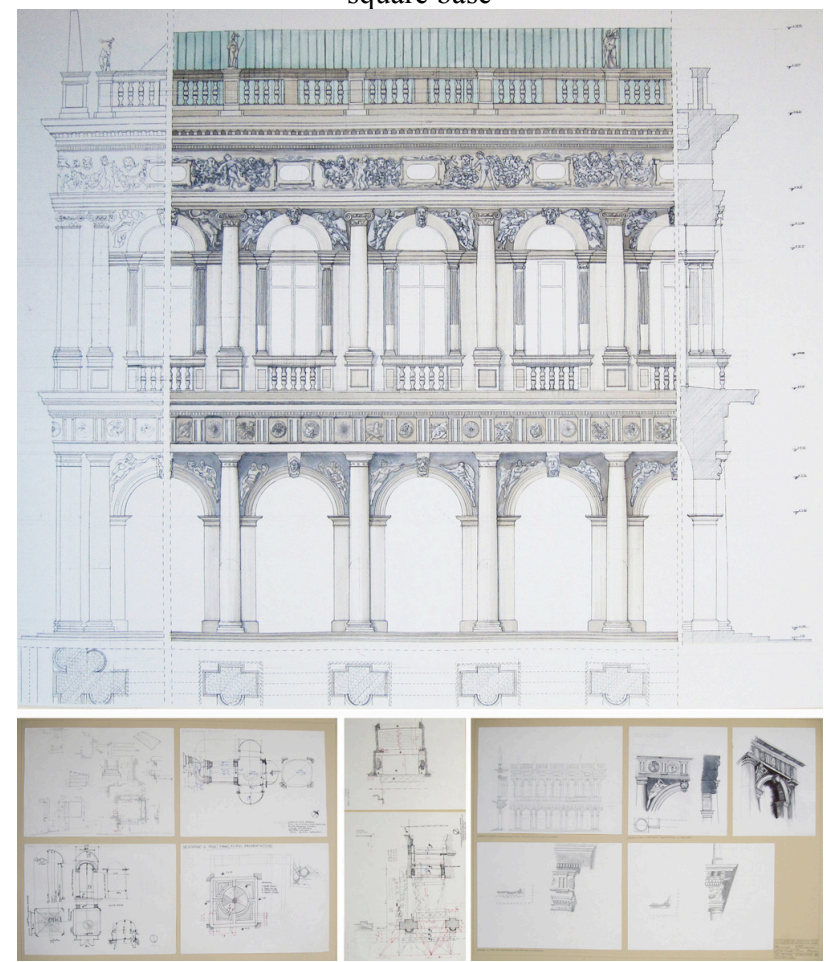

Figure 6 - Collection of perceptual, visual, metric and dimensional data of the Biblioteca Marciana in Venice, Italy. Course of Architectural Drawing, IUAV University of Venice (De Masi, A.)

\subsection{Formal, Geometric and Proportional Study}

The drawings and models previously described enabled the start of new studies focused on the analysis of the form, the constructive geometry and proportions of the historical buildings in Milan and Venice, Italy. In particular, in the search for a form of proportional basis, of the main axes and their mutual relationship. The geometrical analysis of the shapes has therefore been supplemented by a metrology study in order to verify the existence of a geometric matrix of the project, of a reference module and identify similarities with similar architectures in a synchronic temporal space. It would have been appropriate to extend the analysis to the study of the walls and the equipment connected to them in order to define the 

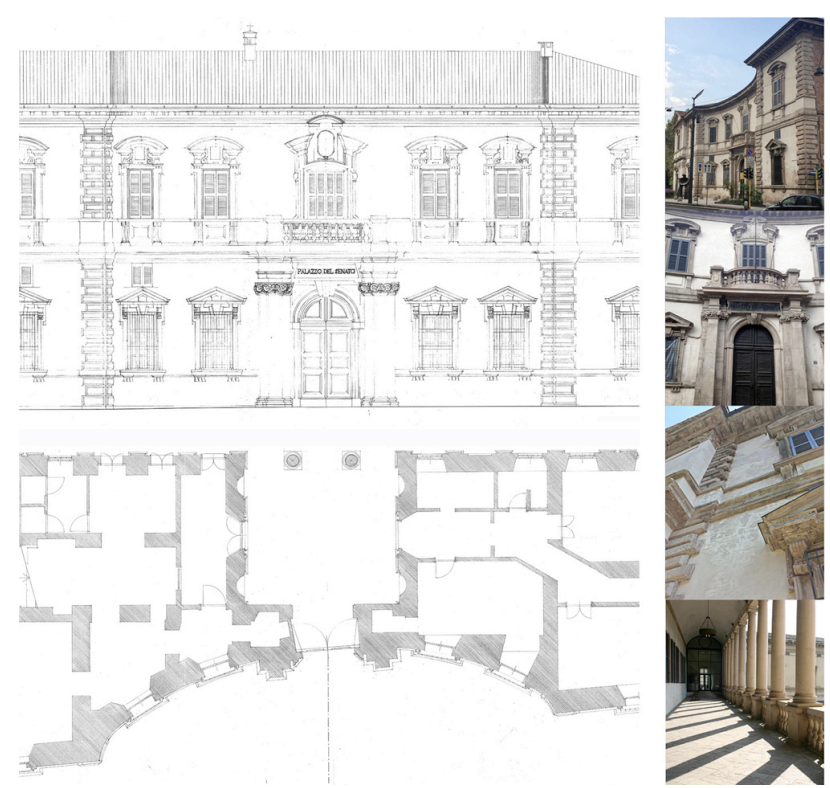

Figure 7 - Architectural Survey of the Senate Palace in Milan, Italy. Course of Drawing, Milan Polytechnic (De Masi, A.)

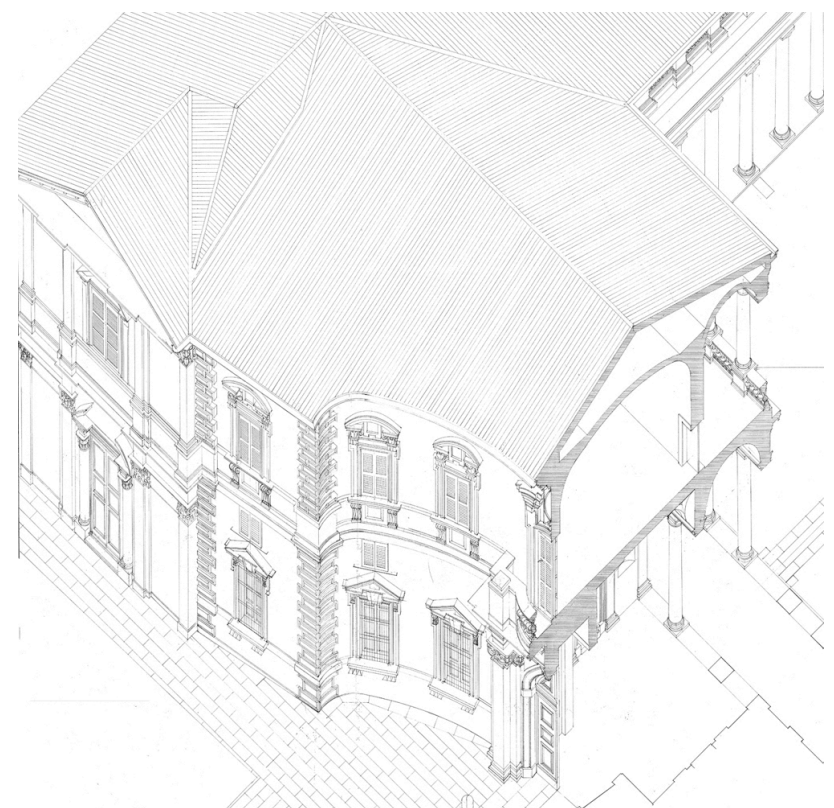

Figure 8 - Isometric Cross section of the Senate Palace in Milan, Italy. Course of Drawing, Milan Polytechnic (De Masi, A.)

construction technique. The next phase focused on the search for a possible unit as key regulator of the entire building. Typically such analysis is started exploiting the presence of architectural elements (such as the order) whose form reveals the proportional scheme of the entire construction; alternatively, one can refer to the hypothetical presence of a certain unit of ancient measurement (foot, palm, cubitus, etc.) derived from sources of different nature. The analysis conducted on the metric-proportional architectural form derived from the order showed a geometric matrix base. (Figures 9, 10)

\subsection{The Route to Knowledge and the Study Steps to Analizing and Monitoring CH's State of Preservation}

knowledge of a CH's state can be reached through various indepths analyses, depending on the accuracy of survey
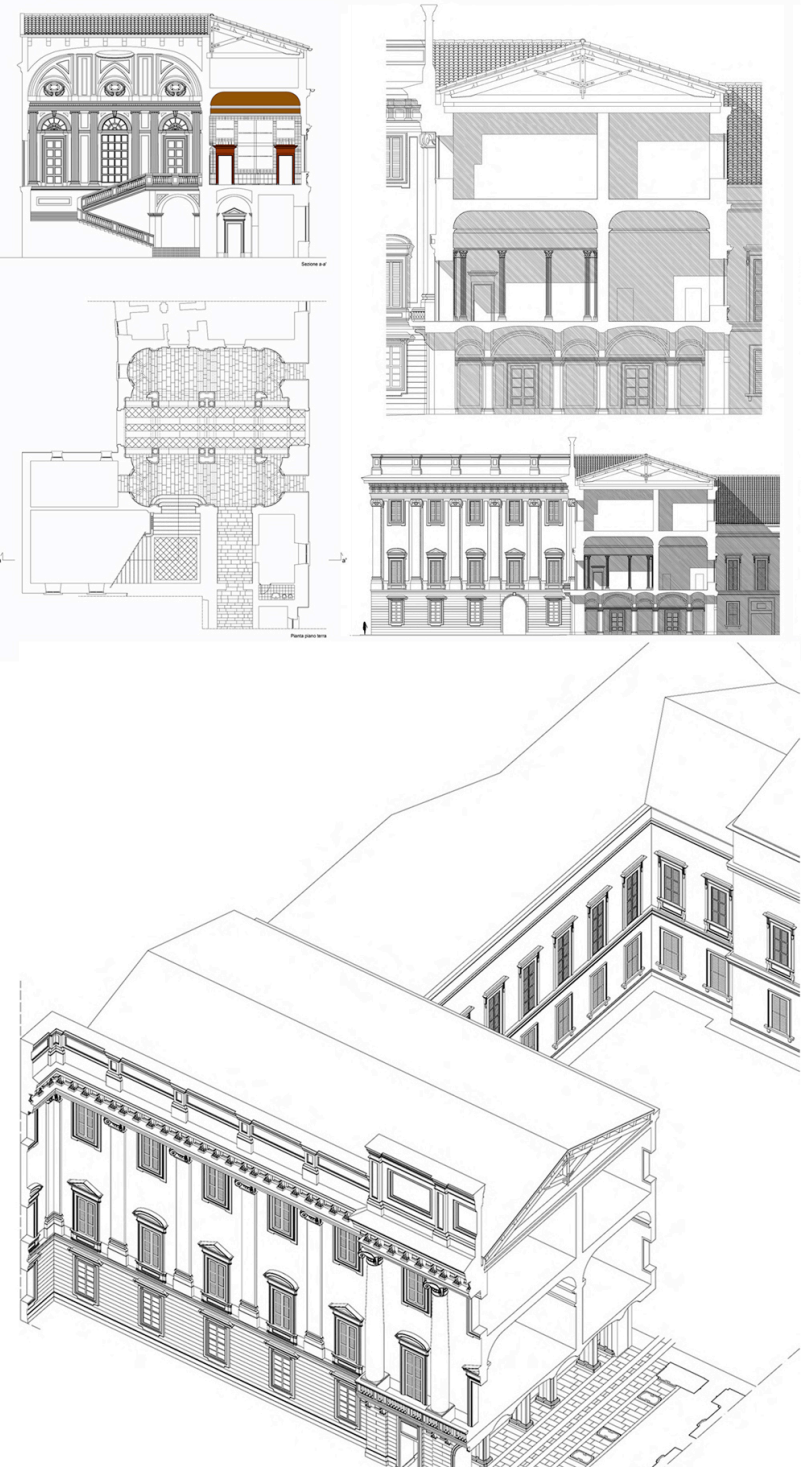

Figure 9 - Royal Palace in Milan, Italy. Dimensional and architectural survey. Course of Drawing, Milan Polytechnic (De Masi, A.)

operations, historical research and experimental investigations. This is to define a model of interpretation that allows a qualitative and quantitative assessment of the structural operation. The difficulties linked to the knowledge of the $\mathrm{CH}$ consists of a retrospective comparison among models of interpretation. The route to knowledge can be traced with the following activities: 1- Identification of building location related to a risk area and to a surrounding urban context. 2- CH's historical evolution as a sequence of the phases of building transformation. 3- The identification of the building's structural elements (materials), of the construction techniques (construction details and connections between the elements). 4The identification of materials, their degradation. 5- Knowledge of subsoil and foundation structures, focusing on the changes that occurred over time and the relative instability. An LS's relief and representation will return an uniformed information from a spatial, a functional, and a thematic point of view. The guidelines for an architectural survey allow to document historic monuments information through advanced 3D recording techniques and reality-based modelling. They also allow to identify, preserve, protect and sustain collective architectural and archaeological heritage. 

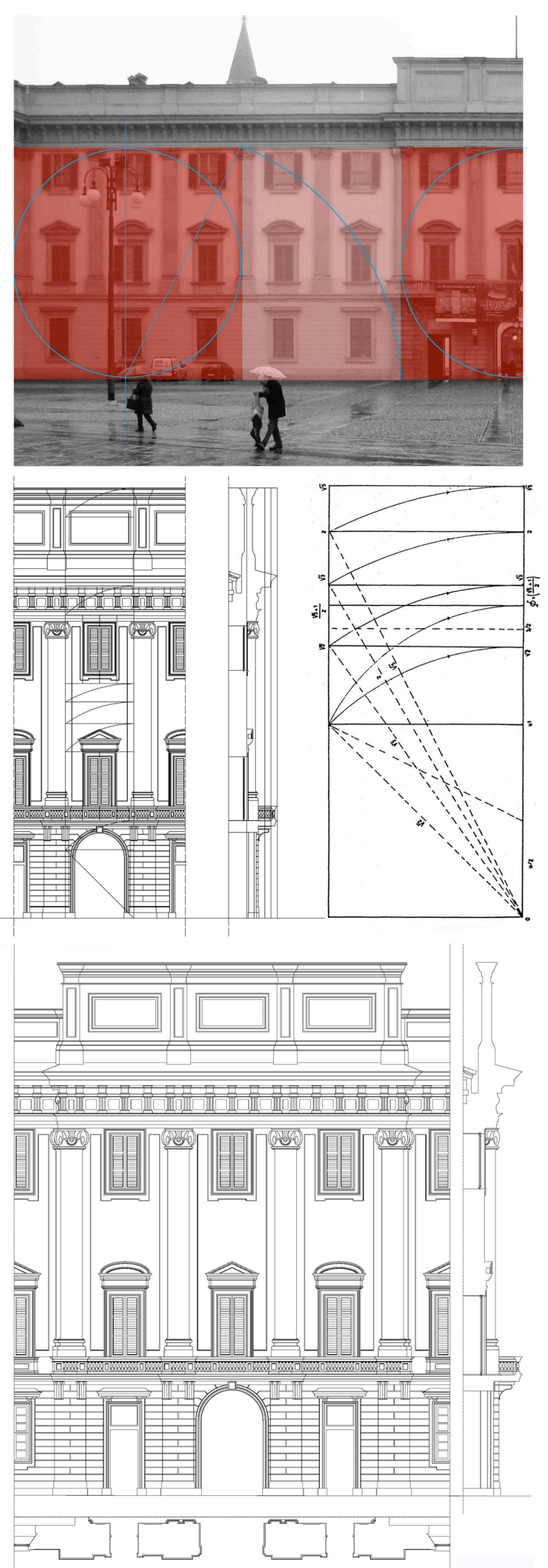

Figure 10 - Royal Palace in Milan, Italy. Architectural survey and proportioning schemes based on tilting the diagonal of the square base and that of successive rectangles. Course of Drawing, Milan Polytechnic (De Masi, A.)
A survey should look beyond buildings to include the aspects of the Urban Landscape in which monuments study is inserted. General Inventory and Survey Guidelines of Historic Monuments to provide information and data record for a wide range of historic buildings/monuments. The records can be used by scholars to identify: 1 - the state's heritage, 2 - evaluate the heritage, 3- Milan's history and culture. 4- plan for its preservation. The LS were divided into the following categories (additional information has been obtained by the Italian Ministry of Heritage and Cultural Activities's programs and by the Standards and Guidelines for Architectural and Historical Investigations in Maryland (GAHI), USA representing the actual state of preservation of protected $\mathrm{CH}$ ): 1) Historical documentation research of archival sources with attention to the relationship between work and context. 2) Photographic survey of the different facades, of the roof, of the entrance, and of the staircase. 3) Registry identification for a three-parametric evaluation: denomination, toponymy and land registry data. In particular: Section a - "Name of Property" for identifies the various names by which the property has been known nel tempo. Section b - "Geographical Location". Section c "Owner of the Building". Section 4 - "Legal Description". Section d - "Primary Location of Additional Data". Section 6 "Classification detail" [District (with a significant linkage, or continuity of buildings, structures, or objects united historically or aesthetically), Buildings, Structure (this is used to distinguish from buildings those functional constructions), Site (it is a prehistoric or historic occupation or activity where the location itself possesses historic, cultural, or archeological value), Object (it are primarily artistic in nature or are relatively small in scale)] (GAHI). Section e- "Buldings Description" [Condition, Narrative Description/Architectural survey (for a narrative describing the building and its physical characteristics as it exists today, noting the features which create the historic character plus changes that have been made over time and the impact of those changes on the historic character) (GAHI). Section $f-$ "Buildings Significance" [Period of Significance, Areas of Significance (Agriculture, Architecture, Archeology, Art, Commerce, Conservation, Economics, Education, Engineering, Recreation, Health/Medicin), Specific dates, Evaluation, Applicable Criteria for Evaluation, Statement of Significance (GAHI). Section g -"Bibliographical References". 4) Sensitivity factors in order to evaluate: a) a relationship between manufacts and territorial context; b) geographic, geomorphological, and antropic characteristics; c) accessibility. 5) Current formal aspect with the subcategories related to dimensional factors of the facade height and the type of hedge; study of the geometrical relationship between full and empty areas through information about the number and the shape of the original openings compared to the modified ones; horizontal and vertical alignments and study of the openings axle spacing with an indication of the pace; geometry and proportion for architectural details and for the facade significant profiles; dimensional scale survey of the compartment; dimensional relief with drafting of the plan, sections and elevations (scale1:50); Relief with drafting of the architectural plan, sections and elevations (scales 1:50, 1:25). Specifically: a- size, height, and number of bays, roof form, and principal materials. b- Exterior façade in logical order with fenestration, materials and decorative elements. c-description of the exterior of any wings or additions. It is often easier to describe the principal section, or main block, in its entirety and then move to later sections. 4- Describe the interior of the main structure. Begin with the ground floor, and always start by describing the floor plan through a conventional terminology created by the Ente Italiano di Formazione (UNI). Draw the ground floor stair in order to make it as a check mark for the next floor. Describe 
each successive floor in a logical order. It is usually best to begin with the first floor and move up to the attic. 5- Describe the interior of any wings or additions with particular attention should be paid to the spatial and functional relationship of the wing to the house. After the house has been described, move out into the yard. Describe any outbuildings or farm buildings that are considered significant, as well as historic landscape features (GAHI). Other issues include: a- Deterioration of the property's historic integrity. b- Date of restoration. c- the historical basis for the work done. $d$ - the amount of remaining historic material and replacement material. e- The effect of the work on the property's historic integrity. f- The historic appearance and current condition of natural features (GAHI). g- landscape features and vegetation that characterized the property (gardens, walls, paths, roadways, grading, fountains, orchards, open spaces, and bodies of water. $\mathrm{h}$ - The historic appearance and current condition of both man-made features and natural features throughout the area. g- Land uses, features, and vegetation that characterized the roadway (GAHI). 6) Constructive aspect with sub-categories related to the survey of constructive and decorative details (scales 1:20 and 1:5); walls relief with respect to materials and finishes, plasters and coatings. 7) Surfaces analysis through a chromatic survey with regard to the type of color, the color shade, and the texture of the material. In this case, it is essential to identify the percentage of the existing colors, their classification code, the areas of degradation, and the amount of degraded surface. 8) Type of building, intended use, pre-existing and current. 9) Current technological aspects. 10) Classification of identity and contemporary signs from the different elements contained in the sub-categories. 11) Registry identification for a three-parametric evaluation: denomination, toponymy and land registry data. 12) Sensitivity factors in order to evaluate: a) a relationship between manufacts and territorial context; b) geographic, geomorphological and antropic characteristics; c) accessibility. 13) Morphology elements in order to identify structural elements, inspectionability, building technique, materials and elements of historic and/or artistic value. 14) Preservation State. LS goal is to provide tools for a proper reading of the building's constructive system, for interpretating the damage causes, and for identifying anomalies and structural instability in order to choose the most suitable form of intervention. About the architectural and historic districts, the following aspects were taken into consideration: 1- Visual frameworks in the urban space (Lynch, 1960): a) Visual plans. b) visual cones. c) Landmarks. d) Main / visual emergencies. e) Visual circumscribed areas. f) Margins / visual barriers. g) Elements of visual disturbance. h) Photographic sequence of the building facades including the building studied and the corresponding profiles. i) Chromaticity of volumes and predominant chromaticity in the stretch of road analyzed. 2- Natural and man-made elements comprising the district, with topographical features and structures, buildings, sites, objects, and other kinds of development. 3- Architectural styles and periods represented and predominant characteristics (proportions, materials, decoration, workmanship, quality of design, etc.) (GAHI). 4General relationship of buildings to each other and to the environment (facade lines, street plans, squares, open spaces, density of development, landscaping, principal vegetation, and important natural features). 5- Appearance of the district during the time with achieved significance and any substantial modifications. 6- Character of the district (residential, commercial, industrial, cultural) and types of buildings and structures. 7- Condition and identity of the buildings, (including alterations, additions, restoration). 8- Qualities of the district and open space such as parks, agricultural areas, vacant lots or ruins that is where relevant activities took place in history or prehistory.

\subsection{Critical Reading of Architectural Surveys and Relief Materials}

The buildings architectural significance is intended as a complete description of stereometric factors, including any cracking phenomena and deformations. Therefore, it involves identifying the plano-elevation aspects of the building blocks. The relief must refer to the geometry of the body rather than to the construction elements. Shall be recognized and represented the possible crack pattern, so as to enable the identification of the causes and possible evolution of the structural problems of the organism. The best scale of representation is 1:50 for a representation of all the qualifying elements. A survey of construction materials is to identify the quality and the conservation state of the components. Such recognition includes collecting pieces of often hidden information through nondestructive investigation techniques, consisting of direct or indirect weakly inspections. A critical reading of the architectural survey and material, along with a study on the results of the aggregate's diachronic evolution, highlights the seismic vulnerability of the building or aggregates. A careful reading of the relieves can actually identify the fundamental spatial connections among the different constituent elements of the aggregate with particular attention to juxtaposition, overlapping and recast building mechanisms. Specifically, this phase will focus on: 1 - The typological transformation system. 2- The formation of aggregated interior spaces. 3- Spatial relationships of the individual cell walls; regularity and modularity at the different floors. 4- The walls alignment, rotations and intersections of the walls axes. 5- Shapes and positions of the openings in the walls.

\subsection{Graphic Processing}

The processing of the 3D data aims at the production of twodimensional drawings, enables to distinguish one uncritical function from others where the capacity and sensitivity of a human operator appears irreplaceable. The critical and conceptual passage is completely identical both in the traditional and in the 3D scanning approach with the choice directly on the object or on the millions of points of its scan to construct a two-dimensional model. The $3 \mathrm{D}$ clouds present a further possibility in the density of the points acquired with the production of screen displays capable of maintaining a strong recognizability. These views can be obtained either by central projection or parallel projection. This latter feature allows to produce a classical orthogonal representations other than parallel projections of 3D clouds. Thus the image of a cloud, properly "cleaned-up", oriented, in scale and dense, can actually be considered a plant, a prospectus or a section. The advantages of this strategy are obvious and relate to the ability to view the cloud so that each point takes the color captured by the digital camera scanner. Representations of this type are essentially images from the screen (snapshot) in high resolution conceptually closer to a traditional technical drawing. From this level you can go to the next involving the CAD vector elements (plan or section) production and processing. In addition, by a simple "subtraction" and projection of the $3 \mathrm{D}$ cloud it is always possible to obtain a non-vector product. Most softwares allow to construct polylines interpolating points of the cloud that lie within a predetermined distance from a reference plane (section plane). These lines, discontinuous because of the characteristics of the sectioned cloud, constitute a basis for a subsequent phase of the "architectural" restitution of the survey. Furthermore, 
they constitute the reference vector on which also the $2 \mathrm{D}$ images, obtained by a parallel projection, can be drawn to scale, and then superimposed to the profile itself. However, these representations, although metrically reliable and "qualitative" rich in information, cannot exhaust the needs of the various parties involved in studies, researches or actions on the object.

\section{Cultural Heritage's Digitization}

Recently have been introduced semi-automated image-based methods such as Structure-From-Motion (SFM) and Dense Multi-View 3D Reconstruction (DMVR) methods. The SFMDMVR (algorithms from unordered image collections) attempts to reconstruct depth from a number of unordered images that depict a static scene or an object from arbitrary viewpoints. The cases study are a attempt for the 3D digitization and representation of two $\mathrm{CH}$ in Milan, Italy. The 3D digitization of the monuments could be performed using photogrammetric survey with multi-image $3 \mathrm{D}$ reconstruction. The position of the two monuments allow the selection of viewpoints for photoshooting around the model. I used Agisoft PhotoScan as software solution for the production of digital 3D replicas of monuments. Infact, the process of capturing require temporary scaffolding for the image-based methodologies. I need to create a complete exterior 3DM of a monument using terrestrial photography. Moreover, I compare the $3 \mathrm{D}$ mesh produced by the SFM-DMVR software against the data I captured using terrestrial 3D laser scanning and total station surveying. For the terrestrial photo shooting session a DSLR Nikon D40 (18-55 $\mathrm{mm}$ lens) has been used with distance of the camera from the monument's surface was estimated at 5 meters. The range scans covered both high and low curvature areas that were enough for validating the quality of the data produced by SFM-DMVR software (Koutsoudis et al.). A total of 400 photographs has been used for the 3D model of the monument 300 and a total of 24 points were measured using a Topcon GPT-3005N total station. The SFM-DMVR software (Version 0.8.5) has been used for this case study. (Figures 11, 12)

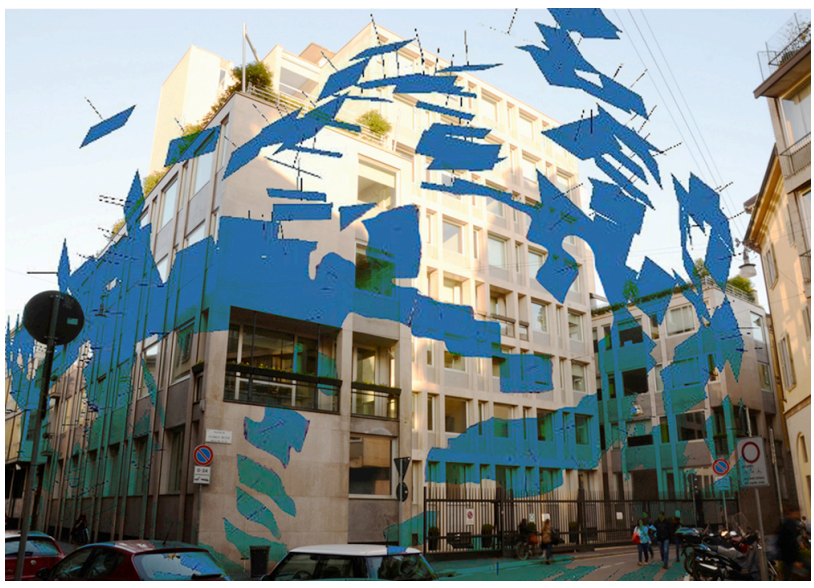

Figure 11 - Central Financial offices "La Centrale" (1954-55) in Milan, Italy (architects P. Lingeri, P. G. Bosisio, U. Busca, G. Casalis and C. Maltini). Image position around the building and reconstructed $\mathrm{CH}$ by Smooth Shaded Triangular Mesh and Vertex Painted Medium Quality Triangular Mesh. Course of Architectural Drawing, Milan Polytechnic (De Masi, A.)

\section{Result and Conclusion}

This paper describes reading criteria for the analysis and interpretation of material systems, conditions for evaluation of $\mathrm{CH}$ assets, integrated systems of digital technologies and 2D/3D

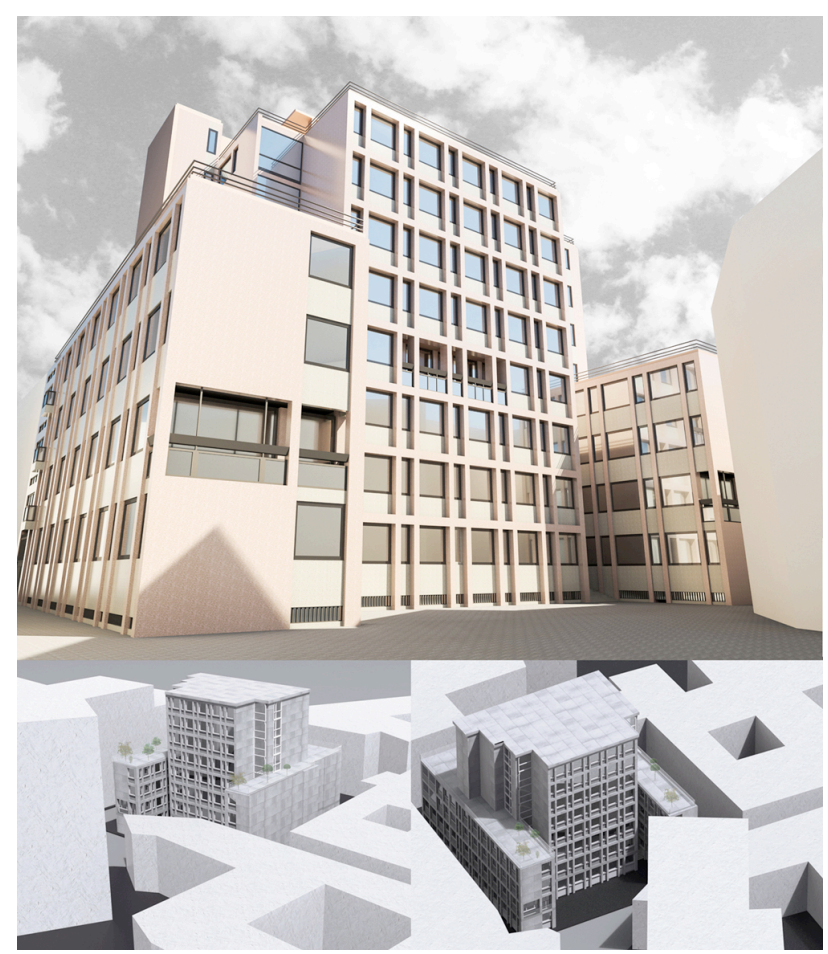

Figure 12 - Central Financial offices "La Centrale" (1954-55) in Milan, Italy (architects P. Lingeri, P. G. Bosisio, U. Busca, G. Casalis and C. Maltini). Architectural Model. Course of Architectural Drawing, Milan Polytechnic (De Masi, A.)

digitization of $\mathrm{CH}$ and the procedures followed by DRP through graphic analysis and integrated digital survey. The guidelines for an architectural survey allow to organize and document historic monuments information, and to identify the significant cultural/physical elements of our past in order for them to be preserved and protected for future generations. In addition, in this paper the studied projects introduce a combination of virtual technologies and historical reality with experimenting innovative solutions for $\mathrm{CH}$.

\section{REFERENCES}

Bianchini, C. 2001. Modelli Discreti e Modelli Continui nel Rilievo e Rappresentazione Informatizzata dell'architettura. In: Disegnare. Idee immagini, 22, pp. 51-60. Italy.

Brizard, T. Derde and W. Silberman, N. 2007. Basic Guidelines for Cultural Heritage.

Celis, F., Echeverria, E. and Da Casa, F. 2011. Drawing as a Learning System of Architectural Heritage. In: XXIII CIPA Symposium - Prague, Czech Republic - 12/16 September 2011 Proceedings

Celis, F., El dibujo de la Antigüedad, Academia Española de Historia, Arqueología y Bellas Artes, Roma, 1996, 24-27.

Celis, F., Goycoolea, R., Alcalá, la experiencia gráfica en una nueva escuela, Revista EGA nº6, Valencia, 2001, 114-116 Echeverría, E., "Colegio Convento de nuestra Señora del Carmen de los Carmelitas Calzados", Universidad de Alcalá: de las armas a las letras, Alcalá, 2010, 179-185.Coors, V. 2001. Feature-Preserving Simplification in Web-based 3D-GIS. In: Proc. of Int. Symp. On Smart Graphics.

De Masi, A. 2014. Advanced 3d Recording Techniques and Reality-based Modelling of Multi-scale for Digital Preservation of Cultural Heritage and Sites. In: Proc. of 3rd International Conference Heritage 2014. Barcelos, Portugal.

Docci, M. 2009. Disegno e Analisi grafica. Bari: edizione Laterza. 
Docci, M. \& Maestri, D. 2009. Manuale di rilevamento architettonico e urbano: Bari: Laterza.

Foley, J. Van Dam, A. Feiner, S. and Hughes, J. 1995. Computer Graphics: Principles and Practice. In C. AddisonWesley Professional, 2nd Ed.

Guidelines on Cultural Heritage. 2012, JP - Technical report EU/CoE Support to the Promotion of Cultural Diversity.

Kluwer Academic Publishers, 1997, Data Mining and Knowledge Discovery) ${ }^{\circ} \mathrm{c} 199$, Vol. 1, pp. 29-53. ISBN:158113-737-0.

Koutsoudis, A. Arnaoutoglou, F. and Remondino, F. 3DICONS: 3D Digitisation of Icons of European Architectural and Archaeological Heritage [Online]. Available: 3diconsproject.eu/Artices within reviews.

Lynch, K. 1960. The Image of the City, Cambridge Massachussettes MIT Press.

Koutsoudis, A. Stavroglou, K. Pavlidis, and G. Chamzas, C. 2011. 3DSSE - A 3D Scene Search Engine - Exploring 3D Scenes Using Keywords. In Journal of Cultural Heritage.

ICOMOS Charter for Interpretation and Presentation of Cultural Heritage Sites (www.enamecharter.org) Professionals in the Use of Information Technologies.

Letellier, R. 2007. Recording, Documentation, and Information Management for the Conservation of Heritage Places, The Getty Conservation Institute, USA. ISBN: 978-0- 89236-925-6 (pbk.). Marinelli, C. 1991. L'esercizio del Disegno. I Vanvitelli, Catalogo Generale del fondo dei disegni della Reggia di Caserta, Leonardo De Luca Editori.

Pavlidis, G. Koutsoudis, A. Arnaoutoglou, F. Tsioukas and V. Chamzas C. 2007. Methods for 3D digitization of Cultural Heritage, JCH, Volume 8, Issue 1, pp. 93-98.

Steffens, M. 2003. Schinkel, K. F., Un Artista al Servizio della Bellezza. Taschen. 